\title{
Clinical and Epidemiological Profile of Death with COVID-19 in Karnali Province of Nepal
}

\author{
Rabin Khadka ${ }^{1 \dagger}$, Laxman Datt Bhatt ${ }^{2 \star}$, Kanchan Thapa ${ }^{3 \dagger}$, Udaya Bahadur BC ${ }^{4,5}$, Chetan Nidhi \\ Wagle $^{5}$
}

Author Info:

${ }^{1}$ Ministry of Health and Population, Department of Health Services, Health Service Directorate, Karnali Province, Nepal

${ }^{2}$ Pokhara University, Department of Healthcare Management, National Open College, Lalitpur, Nepal

${ }^{3}$ Independent Public Health Researcher, Kathmandu, Nepal

${ }^{4}$ Department of Society and Health, Mahidol University, Phutthamonthon, Thailand

${ }^{5}$ Ministry of Social Development (MoSD), Public Health Service

Office Surkhet, Karnali Province, Nepal

tThese authors have equal contribution and share first authorship

Corresponding Author: Laxman Datt Bhatt, Email: laxmanbhattbph@gmail.com

\section{ABSTRACT}

Background: Coronavirus disease (COVID-19) has rapidly spread to many countries and increased mortality worldwide. Most deaths were either elderly or have underlying medical problems and even young individuals have died from COVID-19. We sought to analyze the epidemiological and clinical profiles of COVID-19 related deaths in Karnali Province, Nepal.

Materials and Methods: We studied COVID-19 deaths from 19 May 2020 to 25 December 2020. Information from all districts of Karnali Province were included in this study. Demographic characteristics and geographic distribution map of the death toll in each district over time was analyzed. Quantum GIS(QGIS) 3.16.2 version was used to plot the deaths on maps and IBM SPSS Statistics 25 to perform statistical analysis

Results: As of December 25, 2020, a total of 25 deaths were reported. Mean age of death was 52 (SD 20.99) years. Most of the deaths were distributed in age group of 50 years and above. Additionally, the male to female ratio was $5: 2$. A total of $56 \%$ of the deaths in Karnali were with underlying diseases and was more prominent among males. Most of the cases were centralized in Surkhet district with highest death rate in Birendranagar municipality.

Conclusion: COVID-19 poses a substantial threat to the old age population with co-morbid health condition. The geographical distributions showed that the epidemic in the Surkhet district is more serious than that in the surrounding districts. Case investigation, Contract tracing and dedicated ICU ventilator service for critical cases are essential for response of Pandemic.

Keywords: COVID-19; Karnali Province; Epidemiology; Mortality

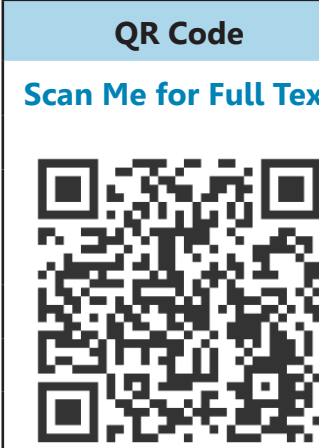 \\ Article Info \\ Scan Me for Full Text Received: 28 December 2020; \\ Accepted: 18 March 2021; Published Online: 19 March 2021 How to cite this article in Vancouver Style? \\ Bhatt LD, Khadka R, Thapa K, BC UB, Wagle CN. Clinical and Epidemiological Features of Death with COVID-19 in Karnali Province of Nepal. Europasian J Med Sci. 2020; 2(COVID-19 Special Issue): 26-2 https:// doi.org/10.46405/ejms.v2i2.00 \\ Disclaimer \\ Conflict of Interest: None Declared \\ Source of Support: Nil \\ Copyright: ( $\ 2020$ by author(s). This is an open access article distributed under the terms of the Creative Commons Attribution International License 4.0@ @ (http://creativecommons.org/licenses/by/4.0/) which permits unrestricted use, distribution, and reproduction in any medium, provided the original work is properly cited. \\ Publisher's Note \\ The Europasian Journal of Medical Sciences (EJMS) (www.europasianjournals.org) is an official Journal of Nirvana Psychosocial Care Center $\&$ Ressearch Institute (www.nirvanapscc.com). The Journal as well as publisher remain neutral with regards to any jurisdictional claims in any published articles, its contents and the institutional affiliations of the authors.}




\section{INTRODUCTION}

Coronaviruses (CoV) incorporates a broad family of viruses responsible for causing illness ranging from the common cold to severe diseases such as Middle East Respiratory Syndrome (MERS-CoV) and Severe Acute Respiratory Syndrome (SARS-CoV). A novel coronavirus (nCoV) is a new strain of Coronavirus (CoV) which has not been antecedently identified in humans. ${ }^{1}$ Most people infected with the COVID-19 virus present with mild to moderate respiratory illness and heal without requiring special treatment. People suffering from underlying medical conditions, like cardiovascular disease, diabetes, chronic respiratory disease, cancer and elderly persons are more likely to develop serious illness. ${ }^{2}$ The term 2019 novel coronavirus was first used by World Health Organization (WHO) on 29 December 2019 that affected the lower respiratory tract of patients with pneumonia in Wuhan, China ${ }^{3}$ and announced that the authorized name of the 2019 novel coronavirus is coronavirus disease (COVID-19) and the public health crisis due to COVID-19 was declared as pandemic on 11 March 2020.4

In Nepal, the first case of COVID-19 was officially reported on 13 January 2020, a 32-year-old Nepalese student returned to Nepal and was studying at Wuhan University of Technology, China. The case presented with cough at the outpatient department of Sukraraj Tropical and Infectious Disease Hospital, Kathmandu however had no history of comorbidities. ${ }^{5}$ On 17 May 2020, a 35 years male who returned from the India found first positive case in Karnali province followed by 3 cases on 22 March, all had travel history from Delhi, India. ${ }^{6}$

As of 25 December 2020, COVID-19 constitute for more than 79 million infections and more than 1.74 million deaths worldwide $7,15 \%$ of cumulative infections and $11 \%$ of cumulative deaths are in South-East Asia. Increasing trends of death were observed in the Western Pacific Region, America, European, and African region, while the South-East Asia and Eastern Mediterranean Regions reported a decrease in both cases and deaths. ${ }^{8}$

The appropriate management of a disease necessitates understanding of its severity and mortality. ${ }^{9}$ This study aimed to analyze the clinical and demographic profiles of the individuals who died as the cause of COVID-19. We used the secondary data from the official report of Ministry of social development (MoSD) and Health service directorate office (HSD), Karnali province.

\section{MATERIALS AND METHODS}

Study design and area: Descriptive crosssectional study was performed from 19 May 2020 to 25 December 2020. All ten districts of Karnali province were included for this study. COVID-19 positive case having permanent address belonging to Karnali province and case who were currently residing Karnali province were included for the study criteria. The Swab collected outside Karnali province and case not residing in Karnali at the time of Polymerase chain reaction (PCR) test result were excluded from this study.

\section{Figure 1: Study site map}

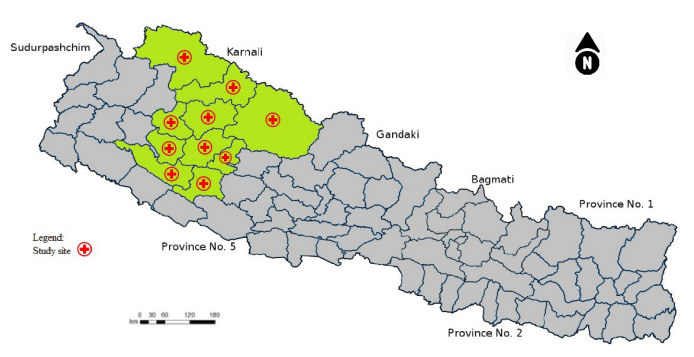

Sample Size: All COVID 19 related deaths during the study period and having confirmed PCR positive results were analyzed in this study.

Data Collection: Health service directorate (HSD) and Ministry of Social Development (MoSD) collected daily COVID-19 situation reports from all local units including, Municipal health section, Rural Municipal Health Section, COVID-19 designated hospitals, Isolation Centers, Public Health Service Office, and health service offices. All the deaths with COVID-19 were reported to Health service directorate office by respective COVID-19 designated hospitals and Isolation centers, death case summary included all the clinical profiles and case demographic information's. All the informations were submitted to HSD for further repository. All the information regarding deaths were further verified by HSD with concerned COVID-19 designated hospitals and isolation centers. Health service directorate stored those death with COVID-19 data once after ensuring its accuracy. We used these secondary data as data source for analysis.

Data analysis: All the data entered in Microsoft Excel, exported to IBM SPSS Statistics version 25 for statistical analysis. Numbers of confirmed cases and death with COVID 19 in province were 
collected. The reported symptoms, demographic characteristics of the deaths including age, sex, travel history and clinical characteristics including clinical symptoms, co-morbidities were analyzed. When a specific parameter was not explicitly obtained, the data were reported as 'not sure'. Quantum GIS(QGIS) version 3.16.2 was used to plot the deaths on map.

\section{Figure 2: Data collection procedure}

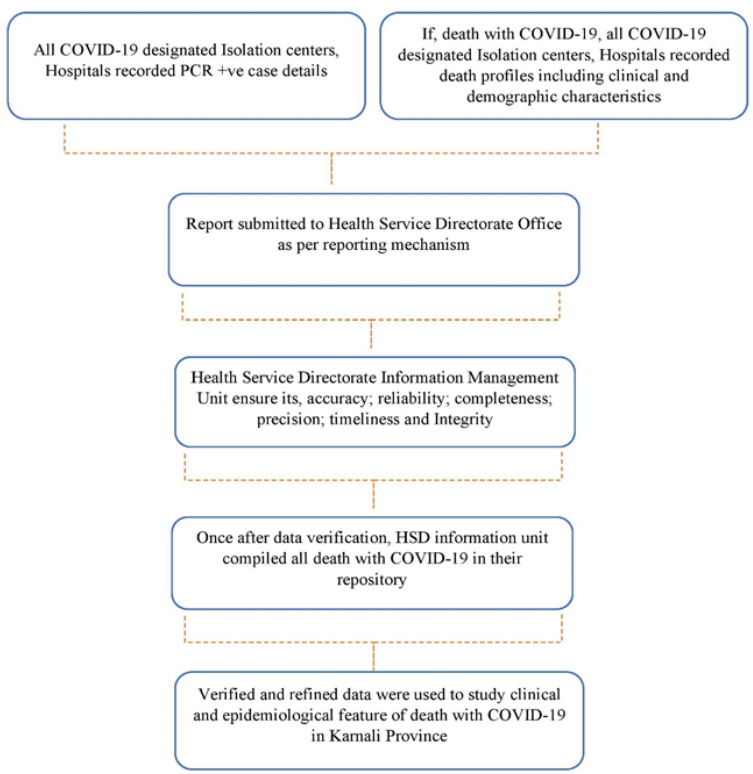

\section{RESULTS}

Among the 7,241 confirmed cases, $0.5 \%$ died from COVID-19 in different districts of Karnali province by December 25, 2020. The first COVID- 19 death in Karnali province was reported on May 29, 2020, a 34 years male from Dailekh district who was in a quarantine and did not have any symptoms. We found the mean age of death was 52 years (SD 20.99). Just over half (52\%) case were 50 years or above age, while rest of the death case were under 50 years age. While, age group distribution of total PCR positive cases was found different with death cases, we found only $10 \%$ of cases were fifty and above whereas remaining were less than fifty (Table 1).

Similarly, table 1 also depicted that nearly three quarters $(73 \%)$ of the cases were male and $27 \%$ were female. More than half $(56 \%)$ of the total deaths were occurred in Brahmin/Chhetri ethnicity followed by Janajati and others (24\% and $16 \%$ respectively), whereas least was found among dalit ethnicity. Comparing the data with PCR positive cases, Brahmin/Chhetri and Janajati were similarly distributed, however Dalit accounted $16 \%$ of total case, Madhesi and others 3\% each and Muslim accounted $1 \%$ of total case.

Clinical characteristics of COVID-19 deaths, we found that nearly three quarters (72\%) of the cases presented with definitive symptoms, among them more than half (52\%) were male. Breathing

Table 1: Socio-demographic characteristics of COVID-19 positive Death in Karnali Province

\begin{tabular}{lcccc}
\hline \multirow{2}{*}{ Variables } & \multicolumn{2}{c}{ Death with COVID-19 } & \multicolumn{2}{c}{ COVID-19 PCR positive cases } \\
\cline { 2 - 5 } & Frequency & Percentage (\%) & Frequency & Percentage (\%) \\
\hline Age (in years) & 12 & 48 & 6490 & 90 \\
\hline$<50$ years (less than 50 years) & 13 & 52 & 751 & 10 \\
$>=50$ years & \multicolumn{5}{c}{} & \\
\hline Sex & 18 & 72 & 5289 & 73 \\
\hline Male & 7 & 28 & 1952 & 27 \\
Female & & & & \\
\hline Ethnicity & 14 & 56 & 4413 & 60 \\
\hline Brahmin/Chhetri & 6 & 24 & 1198 & 17 \\
Janajati & 0 & 0 & 234 & 3 \\
Madhesi & 0 & 0 & 53 & 1 \\
Muslim & 1 & 4 & 1148 & 16 \\
Dalit & 4 & 16 & 195 & 3 \\
\hline Other (not specified) & & & & \\
\hline
\end{tabular}


Table 2: Clinical characteristics of COVID-19 deaths in Karnali province

\begin{tabular}{lcc}
\hline Variables & N & Percent \\
\hline \multicolumn{2}{l}{ Clinical presentation gender wise } & $(\mathbf{n = 2 5 )}$ \\
Asymptomatic Male & 5 & 20 \\
Asymptomatic Female & 2 & 8 \\
Symptomatic Male & 13 & 52 \\
Symptomatic Female & 5 & 20 \\
\hline
\end{tabular}

\section{Clinical presentation total $(n=25)$}

\begin{tabular}{lrr}
\hline Asymptomatic & 7 & 28 \\
Symptomatic & 18 & 72 \\
\hline If symptomatic $(\mathrm{n}=18)$ & & \\
\hline Breathing difficulties & 11 & 61 \\
Fever & 1 & 6 \\
Fever and Cough & 3 & 17 \\
Fever and $\quad$ Breathing & 1 & 6 \\
difficulties & 1 & 6 \\
Pain and Fever & 1 & 6 \\
Stomach pain &
\end{tabular}

\section{Co-morbidities $(\mathbf{n}=\mathbf{2 5})$}

\begin{tabular}{lll}
\hline Yes & 14 & 56 \\
No & 11 & 44 \\
\hline
\end{tabular}

\begin{tabular}{lrr}
\hline If yes(n=14) & & \\
\hline Cancer & 1 & 7 \\
COPD & 5 & 36 \\
Gout & 1 & 7 \\
Hypertension & 1 & 7 \\
Hypertension with Diabetes & 2 & 14 \\
Pulmonary Tuberculosis & 1 & 7 \\
Severe Pneumonia & 3 & 21 \\
\hline Confirmed as COVID-19 Positive(n=25) & \\
\hline Before death & 23 & 92 \\
After death & 2 & 8 \\
Death location & & \\
At hospital & 18 & 72 \\
At home & 6 & 24 \\
At quarantine & 1 & 4 \\
\hline Travel history (n=25) & & \\
\hline India & 5 & 20 \\
National travel history & 10 & 40 \\
No travel history & 10 & 40 \\
Total hospitalization days(n=25) & \\
<7 days (Less than 7 days) & 13 & 24 \\
8-14 days & 62 \\
Not sure & & \\
\hline & & \\
\hline
\end{tabular}

difficulties were the most commonly reported (61\%) symptoms, followed by fever and cough $(17 \%)$, whereas few of the death reported fever, fever with pain and stomach pain (6\% each). More than half of the cases (56\%) had co-morbidities conditions and COPD was predominant, which account $36 \%$ of total co-morbidities conditions followed by severe pneumonia (21\%) and diabetes with hypertension (14\%) (Table 2).

The district wise spatial distribution of death of COVID-19 in Karnali province. A total of 10 administrative districts constitute in Karnali province, of which Humla, Jumla, Dolpa, Mugu and Kalikot have low population density (figure 1).

More than $90 \%$ of the cases were detected COVID-19 positive before death but $8 \%$ of the deaths were recognized as COVID-19 positive after their death, this was due to asymptomatic condition of the case before death.

Figure 3: District wise spatial distribution of deaths with COVID-19 in Karnali province

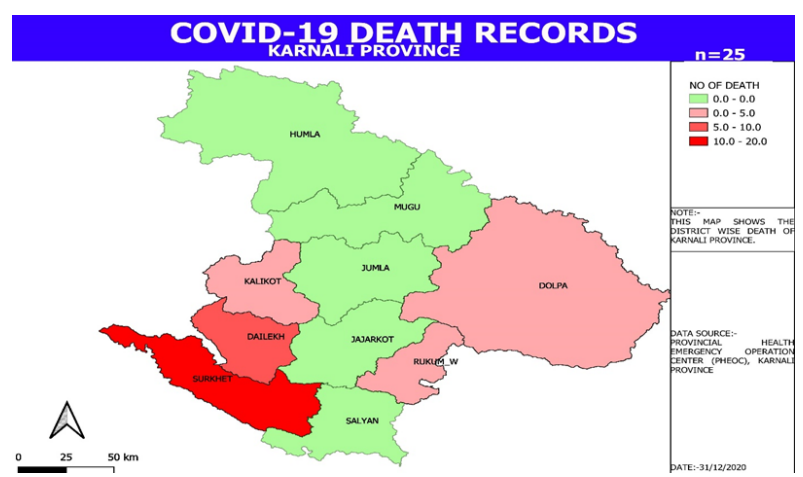

Table 3: District wise case fatality of COVID-19 deaths in Province

\begin{tabular}{lcc}
\hline Variables & Frequency & CFR (\%) \\
\hline Dailekh & 6 & 0.4 \\
Dolpa & 1 & 3.0 \\
Humla & 0 & 0.0 \\
Jajarkot & 0 & 0.0 \\
Jumla & 0 & 0.0 \\
Kalikot & 1 & 0.3 \\
Mugu & 0 & 0.0 \\
Rukum West & 1 & 0.4 \\
Salyan & 0 & 0.0 \\
Surkhet & 16 & 0.5 \\
\hline
\end{tabular}

*Case fatality rate ${ }^{11}$

Number of deaths by disease

Number of case of disease registered $* 100$ 
Most of the case were died at hospital (72\%) but some of the cases were died at home and the quarantine site, which were $24 \%$ and $4 \%$ respectively.

Table 3 illustrated the total COVID-19 specific case fatality rate in Karnali province as of the Manuscript writing date. We found provincial fatality rate $0.34 \%$ of total COVID-19 confirmed case, while national case fatality rate was $0.71 \%$ within our study period. Five district among ten had reported case specific death and Dolpa district reported highest (3\%) followed by Surkhet and Rukum west. The Case specific death might be higher than other district due to less COVID-19 positive case existing with proportion to number of death occurred within our study period.

\section{Figure 4: Palika wise spatial distribution of death case in Karnali province}

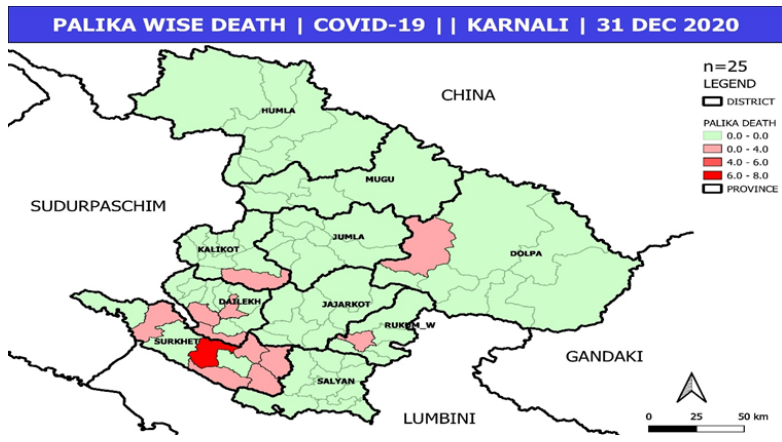

Figure 4 showed spatial distribution of death of COVID-19 in Karnali. Birendranagar Municipality of Surkhet district had highest deaths among other Municipalities, which accounts $36 \%$ of all deaths. Dullu Municipality of Dailekh district and Bheriganga Municipality of Surkhet district had equal proportion of death (12\% for each) followed by Gurvakot Municipality of Surkhet and Guaras Municipality of Dailekh district (8\% each). Remaining were other local units having death proportion of $4 \%$ each.

\section{DISCUSSION}

Province government of Karnali has followed federal governments strategies as well as taken numerous public health measures including provincial lockdown, holding centers at point of entry, identification of possible hotspots and PCR testing, revitalization of provincial Rapid Response Team (RRT) and Case investigation, contract tracing to prevent COVID-19 spread into community. NonPharmacological interventions are being followed and quarantine of contacts of infected cases and Institutional as well as home isolation are in practice. ${ }^{6}$

Nearly half of the deaths ensued in people more than 50 years of age. There was nationwide discrepancy amongst the deaths attributed to COVID-19 with a disparity between the developed and developing regions. Higher share of population were found to be elderly in developed countries and, are at substantially higher risk of mortality if infected with COVID-19. Countries like the USA ${ }^{12}$ and Italy ${ }^{13}$ have noticeable proportion of elderly people, aged $>80$ years, accounting for the majority of deaths due to COVID-19; whereas most deaths occurred in patients aged from 50 to 70 years in countries like India ${ }^{14}$, Bangladesh ${ }^{15}$, Brazil $^{16}$ and Iran. ${ }^{17}$ As the life expectancy at birth in Nepal is about 70 years $^{18}$, the results from our analysis of COVID-19 deaths in Nepal is particularly alarming.

We found that definitive symptoms were observed among $72 \%$ of the cases, where breathing (respiratory) difficulties were the most commonly reported symptoms followed by fever. The reported incidence of symptoms in the province were similar with the results reported in China $^{19}$ and Italy ${ }^{15}$ where at least $84 \%$ and $93 \%$ deaths, respectively, occurred in individuals with symptoms.

We further found that most of the individuals who died were diagnosed as SARS-CoV-2-positive before death, this result support the reports from India where more than half of the cases ascertained before death. ${ }^{14}$ However, our study finding do not support with another study that analyzed national data of death with COVID-19 in Nepal from 23 January to 10 August 2020. The study found that nearly half $(49.4 \%)$ of the cases were confirmed as SARS-CoV-2-positive after death ${ }^{9}$ but our study found $8 \%$ of cases were confirmed as SARS-CoV-2 positive after death. This variation within same country might be due to different study periods selected by authors and we might conclude that less number of PCR test in the initial period might had possibility to miss out the death case to be confirmed as SARS-CoV-2-positive death or not.

\section{CONCLUSION}

The clinical and epidemiological profiles of death with COVID-19 indicated that the age and underlying diseases were the most important risk factors for death. Although individuals of all age groups with varied physiological conditions are at risk of disease and death by virus, our 
analysis evident that the severity and mortality of COVID-19 is found higher in age group 50 years or above. older age, weaker immunity, and underlying diseases were the major predisposing factors. Provincial government should prioritize strengthening of community-based surveillance system to minimize further severity of the disease within the community. Special attentions should also be provided to the geriatric population and specific guidelines for this age group for early treatment and prompt critical care service be issued. Also, province need to be more prepared to identify, manage and treat further epidemic/ pandemic diseases in the coming days before the health-care system becomes overwhelmed.

Strength and limitations of the study: Our study is one of the first of its kind in provincial level exploring the epidemiological profile of death cases. and this study evident to federal government for evidence based policy and strategies formulation in response to COVID-19, however due to limited deaths, all the results from this study may not be generalied in national level.

Future scope of the Study: Federal and Provincial government should carry out national level epidemiological study of death with COVID-19.

What is already known on this topic: Limited studies has been conducted in different settings of Nepal in the initial phase of COVID-19 to study the epidemiological and clinical features of death with COVID-19.

What this study adds: This study provides a clear evidence to government stakeholders regarding death with COVID-19, their socio demographic characteristics and actual comorbidities conditions.

Author's contribution: Rabin Khadka, Laxman Datt Bhatt and Kanchan Thapa are equally contributing first author of this study and they responsible for conceptualization of study, methodology finalization, data collection and repository, data analysis, software application, writing an original draft, reviewing and editing, and overall supervision of the research. Uday Bahadur BC and Chetan Nidhi Wagle are responsible for the concept and design of the study, interpretation of results, preparation of the manuscript. All authors read and approved the final manuscript.

Acknowledgements: The authors gratefully acknowledge all the support extended by health coordinators, district COVID-19 focal persons, Case Investigation and Contract Tracing teams, District
Health Officers, District Public/Health Officers, Medical recorders and Information Management and Communication team of Ministry of Social Development Karnali province for restless effort to collect, compile and disseminate daily COVID-19 reports timely. Sincere gratitude to Er. Birodh Kattel for continuous technical support on QGIS Mapping.

\section{REFERENCES}

1. World Health Organization,Regional Office for Eastern Mediterranean. Health Topics. [online] Available at: <http://www.emro.who. int/health-topics/corona-virus/questions-andanswers.html> [Accessed 25 December 2020]. [Full text]

2. Coronavirus [Internet]. Who.int. 2020 [cited 25 December 2020]. Available from: https://www. who.int/health-topics/coronavirus. [Full text]

3. Li Q, Guan X, Wu P, Wang X, Zhou L, Tong Y, Ren R, Leung KS, Lau EH, Wong JY, Xing $X$. Early transmission dynamics in Wuhan, China, of novel coronavirus-infected pneumonia. New England Journal of Medicine. 2020;382:1199-207 10.1056/NEJMoa2001316. [Full text] [PubMed] [PMID]

4. World Health Organization. (2020) Novel Coronavirus (2019-nCoV): situation report, 22. World Health Organization. https://apps.who. int/iris/handle/10665/330991. [Full text]

5. Joshi J, Mishra P, Kamar SB, Sharma ND, Parajuli J, Sharma S, Pandey HR. Clinical Profile of Cases of COVID-19 in Far Western Province of Nepal. Age. 2020 Apr 20;34(20):40. https:// doi.org/10.33314/jnhrc.v18i1.2602. [Full text] [PubMed] [PMID]

6. Ministry of Social Development,Health Service Diretorate,Surkhet.Health sector response to COVID-19. SitRep-(1-3). Accessed 24 December 2020. [Main Site]

7. MoHP. COVID-19 Situtation Reports of Ministry of Health and Population,Government of Nepal:situation report,320.Available online at: https://covid19.mohp.gov.np (accessed December 25, 2020). [Full text]

8. WHO. COVID-19 Weekly Epidemiological Update. 2020;(December-20).Available online at: https://www.who.int/emergencies/ diseases/novel-coronavirus-2019/situationreports.Accessed 26 December 2020. [Full text] 
9. Panthee B, Dhungana $\mathrm{S}$, Panthee $\mathrm{N}$, Gyawali S, Paudel A, Panthee S. Clinical and epidemiological features of COVID-19 deaths in Nepal. New Microbes and New Infections. 2020;38:100797. https://doi.org/10.1016/j. nmni.2020.100797. [Full text] [PubMed] [PMID]

10. Ministry of Social Development,Health Service Diretorate,Surkhet.Health sector response to COVID-19. SitRep-276. Accessed 26 December 2020. [Main Site]

11. DOHS. Health Management Information System,HMIS indicator 2070.Available online at: https://dohs.gov.np/publications/.Accessed 20 December 2020. [Full text]

12. Stokes EK, Zambrano LD, Anderson KN, Marder EP, Raz KM, Felix SE, Tie Y, Fullerton KE. Coronavirus disease 2019 case surveillanceUnited States, January 22-May 30, 2020. Morbidity and Mortality Weekly Report. 2020; 69(24):759. http://dx.doi.org/10.15585/mmwr. mm6924e2. [Full text] [PubMed] [PMID]

13. Onder G, Rezza G, Brusaferro S. Case-fatality rate and characteristics of patients dying in relation to COVID-19 in Italy. Jama. 2020 ;323(18):1775-6. https://doi.org/10.1001/ jama.2020.4683. [Full text] [PubMed] [PMID]

14. Laxminarayan R, Wahl B, Dudala SR, Gopal K, Neelima S, Reddy KJ, Radhakrishnan J, Lewnard JA. Epidemiology and transmission dynamics of COVID-19 in two Indian states. Science. 2020; 370(6517):691-7. https://doi. org/10.1126/science.abd7672. [Full text] [PubMed] [PMID]
15. Dey SK, Rahman MM, Siddiqi UR, Howlader A. Exploring epidemiological behavior of novel coronavirus (COVID-19) outbreak in Bangladesh. SN comprehensive clinical medicine. 2020; 2(10):1724-32. https://doi. org/10.1007/s42399-020-00477-9. [Full text] [PubMed]

16. de Souza WM, Buss LF, da Silva Candido D, Carrera JP, Li S, Zarebski A, Vincenti-Gonzalez M, Messina J, da Silva Sales FC, dos Santos Andrade $\mathrm{P}$, Prete CA. Epidemiological and clinical characteristics of the early phase of the COVID-19 epidemic in Brazil. medRxiv. 2020 2020;4(8):856-65. [Full text]

17. Nikpouraghdam $M$, Farahani AJ, Alishiri G, Heydari S, Ebrahimnia M, Samadinia $H$, Sepandi M, Jafari NJ, Izadi M, Qazvini A, Dorostkar R. Epidemiological characteristics of coronavirus disease 2019 (COVID-19) patients in IRAN: A single center study. Journal of Clinical Virology. 2020;127:104378: https:// doi.org/10.1016/j.jcv.2020.104378. [Full text] [PubMed] [PMID]

18. World Health Organization,Regional Office for Sout East Asia. 2018 Health SDG Profile: Nepal.Available online at: https://apps.who. int/iris/handle. [Full text]

19. Chen L, Yu J, He W, Chen L, Yuan G, Dong F, Chen W, Cao Y, Yang J, Cai L, Wu D. Risk factors for death in 1859 subjects with COVID-19. Leukemia. 2020; 34(8):2173-83. https://doi.org/10.1038/s41375-020-0911-0. [Full text] [PubMed] [PMID] 